\title{
Antidepressant Potentials of Components from Trichilia monadelpha (Thonn.) J.J. de Wilde in Murine Models
}

\author{
Kennedy Kwami Edem Kukuia (D), Jeffrey Amoako Mensah, Patrick Amoateng, \\ Seth Kwabena Amponsah $\mathbb{D}^{D}$, Benoit Banga N'Guessan $\mathbb{D}^{D}$, and Isaac Julius Asiedu-Gyekye
}

Department of Pharmacology and Toxicology, University of Ghana School of Pharmacy, College of Health Sciences, University of Ghana, Accra, Ghana

Correspondence should be addressed to Kennedy Kwami Edem Kukuia; edemkennedy@yahoo.com

Received 29 August 2017; Accepted 28 February 2018; Published 22 April 2018

Academic Editor: Yoshiji Ohta

Copyright (C) 2018 Kennedy Kwami Edem Kukuia et al. This is an open access article distributed under the Creative Commons Attribution License, which permits unrestricted use, distribution, and reproduction in any medium, provided the original work is properly cited.

\begin{abstract}
Trichilia monadelpha is a common medicinal plant used traditionally in treating central nervous system conditions such as epilepsy, depression, pain, and psychosis. In this study, the antidepressant-like effect of crude extracts of the stem bark of T. monadelpha was investigated using two classical murine models, forced swimming test (FST) and tail suspension test (TST). The extracts, petroleum ether, ethyl acetate, and hydroethanolic extracts (30-300 mg/kg, p.o.), standard drug (imipramine; fluoxetine, 3-30 mg/kg, p.o.), and saline (vehicle) were given to mice one hour prior to the acute study. In a separate experiment the components (flavonoids, saponins, alkaloids, tannins, and terpenoids; $30-300 \mathrm{mg} / \mathrm{kg}$, p.o.) from the most efficacious extract fraction were screened to ascertain which components possessed the antidepressant effect. All the extracts and components significantly induced a decline in immobility in the FST and TST, indicative of an antidepressant-like activity. The extracts and some components showed increase in swimming and climbing in the FST as well as a significant enhancement in swinging and/or curling scores in the TST, suggesting a possible involvement of monoaminergic and/or opioidergic activity. This study reveals the antidepressant-like potential of the stem bark extracts and components of T. monadelpha.
\end{abstract}

\section{Introduction}

Depression, a serious psychiatric condition characterized by anhedonia, low mood, and feelings of guilt and of worthlessness, is a leading cause of disability worldwide and has a very significant impact on morbidity, mortality, and health care cost [1]. According to the World Health Organization, depression is projected to be the leading cause of disability worldwide by the year 2020 [2].

The pathophysiology of the disease is very complex and not fully understood $[2,3]$. Several evidences support the notion that disconcertion in serotonin, noradrenaline, and dopamine neurotransmission is responsible for the observed symptoms of depression. Drugs like tricyclic antidepressants, monoamine oxidase inhibitors, and selective serotonin reuptake inhibitors are widely prescribed for depressed patients; however, the efficacy of most of these medications is limited and it takes a number of weeks for these drugs to produce clinically meaningful improvement in the symptoms [4, 5]. In addition, most of these medications are associated with several side effects including dizziness, nausea, sexual dysfunction, dry mouth, and constipation [6]. The situation is further compounded by the fact that an estimated one-third of patients treated with antidepressant fail to show a relief of symptoms [7]. These factors accentuate the need to search for newer, more efficacious, and better tolerated antidepressants [8].

Plants remain the world's chief source of drugs and their usage in alternative medicine is on the rise [9]. Medicinal plants may provide essential alternative sources for treating depression with greater efficacy and fewer side effects $[10,11]$. These medicinal plants produce diverse range of biologically active components that demonstrate beneficial pharmacological effects in man [12]. Several advantages of plant components with regard to the discovery of antidepressants have been reported and the antidepressant activity of 
plant phytochemical in particular has attracted tremendous attention in recent years [13]. In recent years, phytochemicals such as flavonoids, saponins, alkaloids, and terpenoids extracted from some medicinal plants have been reported to exhibit antidepressant-like effect in various animal models of depression [14-17].

The stem bark of Trichilia monadelpha (Thonn.) J.J. de Wilde (family: Meliaceae) is used traditionally in the treatment of some central nervous system (CNS) conditions such as depression, epilepsy, psychosis, pain, and inflammation [18]. Some of the investigated pharmacological effects of the plant include antioxidant, wound healing, analgesic, anti-inflammatory, and antianaphylactic properties $[19,20]$. Although oxidative stress, inflammation, and so on have been implicated in depression, the antidepressant potential of Trichilia monadelpha, which has shown antioxidant and anti-inflammatory activities, is yet to be investigated. The study thus seeks to investigate the antidepressant activity of the crude extracts and components of the stem bark of T. monadelpha using the two classical acute models of depression, the forced swimming, and tail suspension tests.

\section{Materials and Methods}

2.1. Preparation of Stem Bark Extracts. The stem bark (together with other plant parts) of T. monadelpha was collected from Bomaa, Brong-Ahafo Region, Ghana $\left(7^{\circ} 05^{\prime} 06.60^{\prime \prime} \mathrm{N}\right.$, $\left.2^{\circ} 10^{\prime} 01.66^{\prime \prime} \mathrm{W}\right)$, and authenticated at the Ghana Herbarium, Department of Botany, University of Ghana (Voucher number DPT/JM/001). The plant bark was then chopped into pieces, sun dried for fourteen days, and pulverized into fine powder. The powdered plant bark was serially extracted with petroleum ether at $40-60^{\circ} \mathrm{C}$, ethyl acetate, and $70 \%$ ethanol over a 24-hour period using the cold maceration technique. The resulting extracts were subsequently concentrated under reduced pressure at $40-60^{\circ} \mathrm{C}$ to a dark brown syrupy mass in a rotary evaporator. The syrupy mass was further dried using water bath and kept in a desiccator till ready for use. The resulting yields were $0.49 \% \mathrm{w} / \mathrm{w}$ for petroleum ether extract (PEE), $0.6 \% \mathrm{w} / \mathrm{w}$ for ethyl acetate extract (EAE), and $7.3 \% \mathrm{w} / \mathrm{w}$ for hydroethanolic extract (HEE).

2.2. Animal Husbandry. ICR mice (20-25g) were obtained from the Noguchi Memorial Institute for Medical Research, University of Ghana, and kept at the animal house of the School of Biomedical and Allied Health Science, University of Ghana. The animals were kept in stainless steel cages $(47 \mathrm{~cm} \times 34 \mathrm{~cm} \times 18 \mathrm{~cm})$ under standard conditions: $12 \mathrm{hr}$ light/darkness cycles, access to normal commercial feed and water ad libitum, and a constant temperature $\left(20-23^{\circ} \mathrm{C}\right)$. All animals used in this study were handled according to the Guide for the Care and Use of Laboratory Animals [21]. Ethical clearance was received from the National Institutional Animal Care and Use Committee, Noguchi Memorial Institute for Medical Research, University of Ghana, with protocol number 2014-02-4N.

2.3. Preliminary Phytochemical Screening. The extracts were screened for the presence of phytochemical constituents such as alkaloids, saponins, glycosides, tannins, sterols, flavonoids, and terpenoids as described by Trease and Evans [22].

2.4. Place and Time of Experimentation. All behavioural studies were done with experimentally naïve mice at the Neuropsychopharmacology Research Laboratory, Department of Pharmacology and Toxicology, University of Ghana School of Pharmacy, and in the light cycle between 7:30 a.m. and 3:30 p.m.

2.5. Drugs. Fluoxetine hydrochloride (Prozac) was from Eli Lilly and Co., Basingstoke, England; imipramine hydrochloride (Tofranil) from Mallinckrodt Pharmaceuticals, Ireland.

2.6. Primary Observation Test. The behavioural and neuroactive effect of the extracts was first evaluated according to standardized observation grid similar to that described by Irwin [23]. ICR mice were randomly divided into various groups $(n=7)$ and kept in the experimental environment for 7 days to acclimatize. Animals were then fasted overnight but had access to water ad libitum and then treated orally with the extracts at various doses $(30-3000 \mathrm{mg} / \mathrm{kg})$. The mice were observed at $0,15,30,60,120$, and $180 \mathrm{~min}$, up to 24 hours after treatment for general changes in behaviour and physiological function as well as mortality. The animals were subsequently assessed for behaviours related to neurotoxicity, CNS stimulation, and depression. Effects on autonomic functions were also noted as well as the lethality of the extracts. From this test the right doses of extracts were selected for the subsequent experiments.

2.7. Tail Suspension Test (TST). The TST was carried out as previously described by Steru et al. [24]. Mice were allowed to acclimatize to the room for 3.5-4 hours before the test. Mice were treated with the various extracts $(30-300 \mathrm{mg} / \mathrm{kg}$ ), fluoxetine (3-30 mg/kg), and vehicle (saline; $10 \mathrm{ml} / \mathrm{kg}$ ). One hour after oral administration of the test drugs, mice were subsequently suspended be the tail individually from a horizontal bar (distance from floor is $30 \mathrm{~cm}$ ) using adhesive tape (distance from tip of tail is $1 \mathrm{~cm}$ ). Duration of immobility (defined as the absence of all movements except those required for respiration), curling, and swinging behaviour was recorded by an observer for $5 \mathrm{~min}$ from video recordings of the test with the aid of public domain software JWatcher Version 1.0. Decline in immobility score was the index for antidepressant effect; increase in curling behaviour was suggestive of opioidergic activity.

2.8. Forced Swimming Test (FST). The FST was based on that described by Porsolt et al. [25]. Mice were also divided into groups of 7 animals each and received the vehicle (saline), various extracts $(30-300 \mathrm{mg} / \mathrm{kg}$ ), or reference drug fluoxetine $(3-30 \mathrm{mg} / \mathrm{kg})$. One hour after the oral administration of the test drugs, mice were then gently dropped individually into transparent cylindrical polyethylene tanks $(25 \mathrm{~cm}$ high, $10 \mathrm{~cm}$ internal diameter) containing water $\left(20-23^{\circ} \mathrm{C}\right)$ up to a level of $20 \mathrm{~cm}$ and allowed to swim for $5 \mathrm{~min}$. Each session was then recorded by a video camera suspended approximately $100 \mathrm{~cm}$ above the cylinders. The mean immobility score 
(when the mouse was floating upright and made only small movements to keep its head above the water), swimming score (active horizontal movements), and climbing score (active vertical movements) during the 6 min test were then scored, with the aid of public domain software JWatcher Version 1.0 (University of California, Los Angeles, USA, and Macquarie University, Sydney, Australia. Available at http://www.jwatcher.ucla.edu/). A reduction in immobility score was an indication of antidepressant effect. An increase in climbing score without commensurate change in swimming behaviour is suggestive of adrenergic mechanisms while an increase in swimming score without change in climbing suggests serotoninergic interactions.

\subsection{Extraction of Components from the Most Efficacious Crude Extract}

2.9.1. Saponins (by the Method of Nahapetian and Bassiri [26]). Fifty (50 g) of hydroethanolic extract was dispersed in $500 \mathrm{ml}$ of $20 \%$ ethanol. The suspension was then heated over a hot water bath for 4 hours with continuous stirring at about $55^{\circ} \mathrm{C}$. The mixture was filtered and the residue reextracted with another $500 \mathrm{ml}$ of $20 \%$ ethanol. The combined extracts were then reduced to $40 \mathrm{ml}$ over water bath at about $90^{\circ} \mathrm{C}$. The concentrate was then transferred into a $500 \mathrm{ml}$ separating funnel and a volume of $50 \mathrm{ml}$ diethyl ether was added and shaken vigorously. The aqueous layer was recovered while the ether layer discarded. The purification process was repeated. Sixty (60) $\mathrm{ml}$ of $\mathrm{n}$-butanol was added to the remaining fraction. The resulting solution was washed twice with $10 \mathrm{ml}$ of $5 \%$ aqueous sodium chloride. The remaining solution was heated in a water bath. After evaporation the sample was dried in the oven into a constant weight.

\subsubsection{Alkaloids (by the Method of Obadoni and Ochuko [27];} Harborne [28]). Fifty (50 g) of the hydroethanolic extract was weighed into a beaker. A volume of $1000 \mathrm{ml}$ of $10 \%$ acetic acid in ethanol was added, covered, and allowed to stand for 4 hours. The solution was filtered and the resulting filtrate was concentrated on a water bath to about one-quarter of the original volume. Concentrated ammonium hydroxide was added drop wise until the formation of a precipitate was complete. The whole solution was allowed to settle and the precipitate was collected and washed with dilute ammonium hydroxide and then filtered. The residue was then collected and dried as alkaloids.

2.9.3. Flavonoids (by the Method of Bohm and KocipaiAbyazan [29]). Fifty (50 g) of the hydroethanolic extract was twice extracted with $500 \mathrm{ml}$ of $80 \%$ aqueous methanol at room temperature. The whole solution was filtered through Whatman filter paper number $42(125 \mathrm{~mm})$. The filtrate was later transferred into a crucible and evaporated into dryness over a water bath and weighed to a constant weight.

2.9.4. Terpenoids (by the Method of Ferguson [30]). An amount of the hydroethanolic extract, $50 \mathrm{~g}$ was soaked in ethanol for 24 hours. The resulting solution was filtered; the filtrate was extracted with petroleum ether. The ether extract was treated as total terpenoids.

2.9.5. Tannins (by Method of Strumeyer and Malin [31]). Fifty $(50 \mathrm{~g})$ of crude hydroethanolic extract was weighed into a flask and $500 \mathrm{ml}$ of $80 \%$ acetone (v/v) was added. The resulting solution was placed in a water bath at $70^{\circ} \mathrm{C}$ and carefully shaken for 15 minutes. After cooling, the supernatant was decanted carefully. The extraction was repeated twice and the supernatants were combined and concentrated using a rotary evaporator at $40^{\circ} \mathrm{C}$ to obtain the crude phenolic fraction. The crude phenolic extract $(2.5 \mathrm{~g})$ was dissolved in $20 \mathrm{ml}$ of ethanol and applied on a column packed with $40 \mathrm{~g}$ of Sephadex LH-20 gel. Ethanol was used as first eluent, to allow the removal of lower molecular weight phenolic compounds. Then $50 \%$ acetone in water $(\mathrm{v} / \mathrm{v})$ was used to elute tannins.

2.10. Statistical Analysis. GraphPad Prism for windows version 5.03 (GraphPad Software, San Diego, CA, USA) was used for all data and statistical analysis. $P<0.05$ was considered statistically significant. Differences in means were analyzed by ANOVA followed by post hoc test. Doses for $50 \%$ of the maximal effect $\left(\mathrm{ED}_{50}\right)$ for each drug were determined by using an iterative computer least square method, with the following nonlinear regression (three-parameter logistic) equation:

$$
Y=\frac{a+(b-a)}{\left(1+10^{\left(\log \mathrm{ED}_{50}-X\right)}\right)},
$$

where $X$ is the logarithm of dose and $Y$ is the response. $Y$ starts at $a$ (the bottom) and goes to $b$ (the top) with a sigmoid shape.

\section{Results}

3.1. Phytochemical Screening. Preliminary phytochemical screening revealed the presence of alkaloids, flavonoids, glycosides, saponins, sterols, tannins, and terpenoids in HEE. EAE had alkaloids, glycosides, tannins, sterols, and terpenoids while PEE showed the presence of alkaloids, sterols, and terpenoids (Table 1).

3.2. Irwin Test. No signs of toxic effects were manifested during the 24 hour observation period for all the three extracts. Extract-treated mice showed signs of sedation at $300-3000 \mathrm{mg} / \mathrm{kg}$. There were signs of analgesic effects as well frequent urination and defecation in all three extracts. No death was also recorded after 24 hours for all the administered doses in all the three extracts (Table 2).

\subsection{Neurobehavioural Effects of the Crude Extracts in the Tail Suspension Test (TST)}

3.3.1. Mean Immobility Score. All three extracts (PEE, EAE, and HEE) significantly decreased immobility score $\left(F_{9,60}=\right.$ $55.11 P<0.0001 ; F_{9,60}=66.02 P<0.0001 ; F_{9,60}=34.83 P<$ 0.0001 , resp.; Figure 1). In the TST, the order of antidepressant 

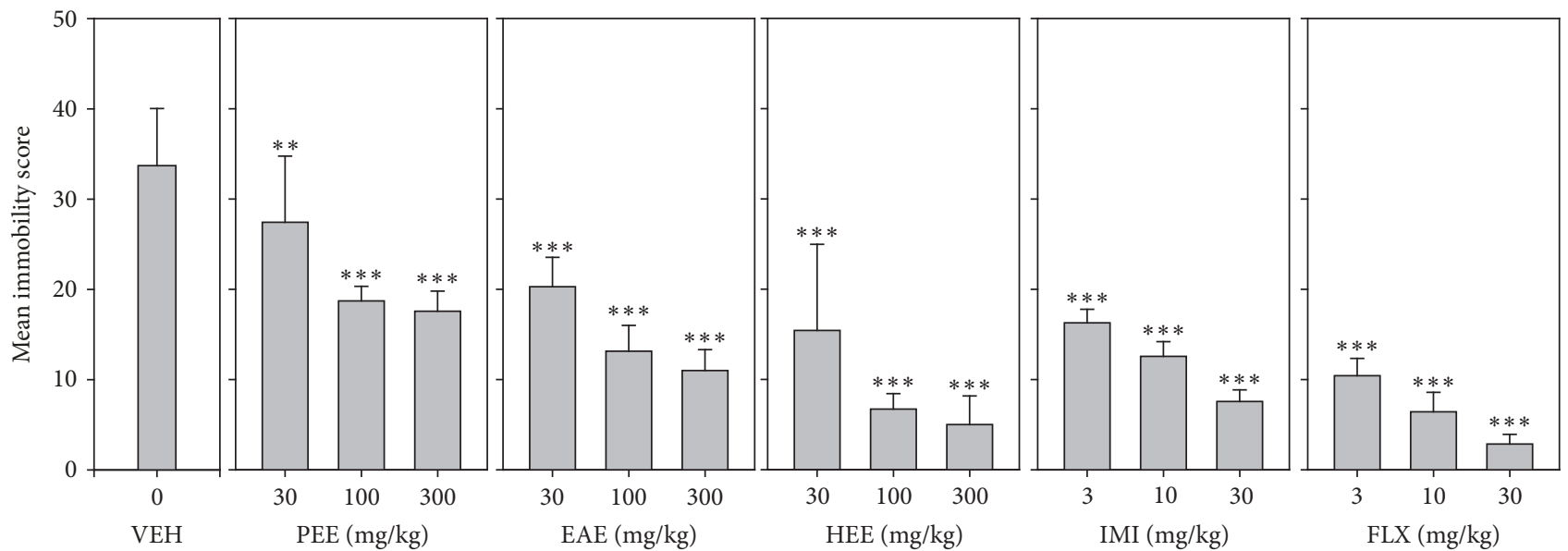

Figure 1: Effects of the extracts, PEE (30-300 mg/kg), EAE (30-300 mg/kg), and HEE (30-300 mg/kg), fluoxetine (3-30 mg/kg), and imipramine $(3-30 \mathrm{mg} / \mathrm{kg})$ on immobility score in TST. Data are represented as group means \pm SEM $(n=7)$. Significantly different from vehicle: ${ }^{* * *} P<0.0001 ;{ }^{* *} P<0.001$ (one-way ANOVA followed by Newman-Keuls test).

TABle 1: Preliminary phytochemical screening crude HEE, EAE, and PEE from the stem bark of Trichilia monadelpha.

\begin{tabular}{lccc}
\hline Constituents & HEE & Inference & \\
& EAE & PEE \\
\hline Alkaloids & Present & Present & Present \\
Saponins & Present & Absent & Absent \\
Flavonoids & Present & Absent & Absent \\
Tannins & Present & Present & Absent \\
Glycosides & Present & Present & Absent \\
Terpenoids & Present & Present & Present \\
Sterols & Present & Present & Present \\
\hline
\end{tabular}

efficacy calculated from the log-dose response curves was fluoxetine $>$ imipramine $>$ HEE $>$ EAE $>$ PEE (Table 3).

\subsubsection{Possible Contribution of Monoaminergic and Opioidergic} Mechanisms in Antidepressant Effect: Mean Swinging and Curling Scores. All three extracts (PEE, EAE, and HEE) induced significant increases in swinging $\left(F_{9,60}=57.83 P<\right.$ $0.0001 ; F_{9,60}=44.30 P<0.0001 ; F_{9,60}=16.15 P<0.0001$, resp.) scores in mice (Figure 2). Similar effects were observed for fluoxetine and imipramine (Figure 2). Again all three extracts exhibited significant increases in curling score $\left(F_{9,60}\right.$ $=8.236 P<0.0001 ; F_{9,60}=44.85 P<0.0001 ; F_{9,60}=12.59$ $P<0.0001$, resp.). In contrast, fluoxetine and imipramine did not affect mean curling scores.

\subsection{Neurobehavioural Effects of the Crude Extracts in the Forced Swimming Test (FST)}

3.4.1. Mean Immobility Score. All three extracts, (PEE, EAE, and HEE) significantly decreased immobility score $\left(F_{9,60}=\right.$ $87.33 P<0.0001 ; F_{9,60}=95.33 P<0.0001 ; F_{9,60}=81.73 P<$ 0.0001 , resp.) in a dose-dependent manner (Figure 3 ).
In the FST, the order of antidepressant efficacy calculated from the dose response curves with regard to immobility was fluoxetine $>$ HEE $>$ imipramine $>$ EAE $>$ PEE (Table 3).

3.4.2. Possible Contribution of Serotoninergic and Noradrenergic Mechanisms in Antidepressant Effect: Mean Swimming and Climbing Scores. All three extracts (PEE, EAE, and HEE) showed a significant increase in swimming $\left(F_{9,60}=82.04\right.$ $P<0.0001 ; F_{9,60}=108.1 P<0.0001 ; F_{9,60}=55.06$ $P<0.0001$, resp.) scores. Both fluoxetine and imipramine induced increased swimming behaviour. Similarly, all three extracts significantly increase mean climbing scores just as imipramine. In contrast, fluoxetine did not have an effect on climbing behaviour. Refer to Figure 4.

\subsection{Neurobehavioural Effects of the Components \\ Extracted from HEE in the Tail Suspension Test (TST)}

3.5.1. Mean Immobility Score. Three components, SAP, FLV, and ALK, significantly decreased immobility score $\left(F_{9,60}=\right.$ $82.40 P<0.0001 ; F_{9,60}=154.2 P<0.0001 ; F_{9,60}=100.6$ $P<0.0001$, resp.). Refer to Figure 5. In the TST, the order of antidepressant efficacy calculated from the dose response curves with regard to immobility was fluoxetine $>$ ALK $>$ SAP $>$ FLV $>$ TAN $>$ TER $($ Table 4$)$.

3.5.2. Possible Contribution of Monoaminergic and Opioidergic Mechanisms in Antidepressant Effect: Mean Swinging and Curling Scores. FLV and ALK showed a significant increase in swinging scores $\left(F_{9,60}=78.70 P<0.0001 ; F_{9,60}=50.64\right.$, resp.) (Figure 6(a)). Similar effect was observed for fluoxetine (Figure 6(a)). In contrast, only SAP and ALK exhibited a significant increase in curling scores $\left(F_{9,60}=17.58 P<0.0001\right.$; $F_{9,60}=9.655 P<0.0001$, resp.) (Figure 6(b)). Fluoxetine did not affect mean curling scores. 
TABLE 2: Observations in the acute toxicity test after oral administration of PEE. EAE and HEE of T. monadelpha in mice.

\begin{tabular}{|c|c|c|c|c|c|c|c|c|c|c|c|}
\hline \multicolumn{4}{|c|}{ PEE } & \multicolumn{4}{|c|}{ EAE } & \multicolumn{4}{|c|}{ HEE } \\
\hline $\begin{array}{l}\text { Dose } \\
(\mathrm{mg} / \mathrm{kg})\end{array}$ & $\begin{array}{c}\text { Mortality } \\
\mathrm{D} / \mathrm{T}\end{array}$ & $\begin{array}{l}\text { Latency } \\
\text { (min) }\end{array}$ & $\begin{array}{c}\text { Observed } \\
\text { drug effects }\end{array}$ & $\begin{array}{c}\text { Dose } \\
(\mathrm{mg} / \mathrm{kg})\end{array}$ & $\begin{array}{c}\text { Mortality } \\
\mathrm{D} / \mathrm{T}\end{array}$ & $\begin{array}{l}\text { Latency } \\
(\mathrm{min})\end{array}$ & $\begin{array}{c}\text { Observed } \\
\text { drug effects }\end{array}$ & $\begin{array}{c}\text { Dose } \\
(\mathrm{mg} / \mathrm{kg})\end{array}$ & $\begin{array}{c}\text { Mortality } \\
\mathrm{D} / \mathrm{T}\end{array}$ & $\begin{array}{l}\text { Latency } \\
(\min )\end{array}$ & $\begin{array}{c}\text { Observed } \\
\text { drug effects }\end{array}$ \\
\hline 0 & - & - & - & 0 & - & - & - & 0 & - & - & - \\
\hline 30 & - & 30 & $\begin{array}{l}\text { Analgesia, } \\
\text { urination, } \\
\text { defecation }\end{array}$ & 30 & - & 30 & $\begin{array}{l}\text { Analgesia, } \\
\text { urination, } \\
\text { defecation }\end{array}$ & 30 & - & 30 & $\begin{array}{l}\text { Analgesia, } \\
\text { urination, } \\
\text { defecation }\end{array}$ \\
\hline 100 & - & 15 & $\begin{array}{l}\text { Analgesia, } \\
\text { urination, } \\
\text { defecation }\end{array}$ & 100 & - & 30 & $\begin{array}{l}\text { Analgesia, } \\
\text { urination, } \\
\text { defecation }\end{array}$ & 100 & - & 30 & $\begin{array}{l}\text { Analgesia, } \\
\text { urination, } \\
\text { defecation }\end{array}$ \\
\hline 300 & - & 15 & $\begin{array}{l}\text { Sedation } \\
\text { analgesia, } \\
\text { urination, } \\
\text { defecation }\end{array}$ & 300 & - & 30 & $\begin{array}{l}\text { Sedation } \\
\text { analgesia, } \\
\text { urination, } \\
\text { defecation }\end{array}$ & 300 & - & 30 & $\begin{array}{l}\text { Sedation, } \\
\text { analgesia, } \\
\text { urination, } \\
\text { defecation }\end{array}$ \\
\hline 1000 & - & 15 & $\begin{array}{l}\text { Sedation, } \\
\text { analgesia, } \\
\text { urination, } \\
\text { defecation }\end{array}$ & 1000 & - & 15 & $\begin{array}{l}\text { Sedation, } \\
\text { analgesia, } \\
\text { urination, } \\
\text { defecation }\end{array}$ & 1000 & - & 15 & $\begin{array}{l}\text { Sedation, } \\
\text { analgesia, } \\
\text { urination, } \\
\text { defecation }\end{array}$ \\
\hline 3000 & - & 15 & $\begin{array}{l}\text { Sedation, } \\
\text { analgesia, } \\
\text { urination, } \\
\text { defecation }\end{array}$ & 3000 & - & 15 & $\begin{array}{l}\text { Sedation, } \\
\text { analgesia, } \\
\text { urination, } \\
\text { defecation }\end{array}$ & 3000 & - & 30 & $\begin{array}{l}\text { Sedation, } \\
\text { analgesia, } \\
\text { urination, } \\
\text { defecation }\end{array}$ \\
\hline
\end{tabular}

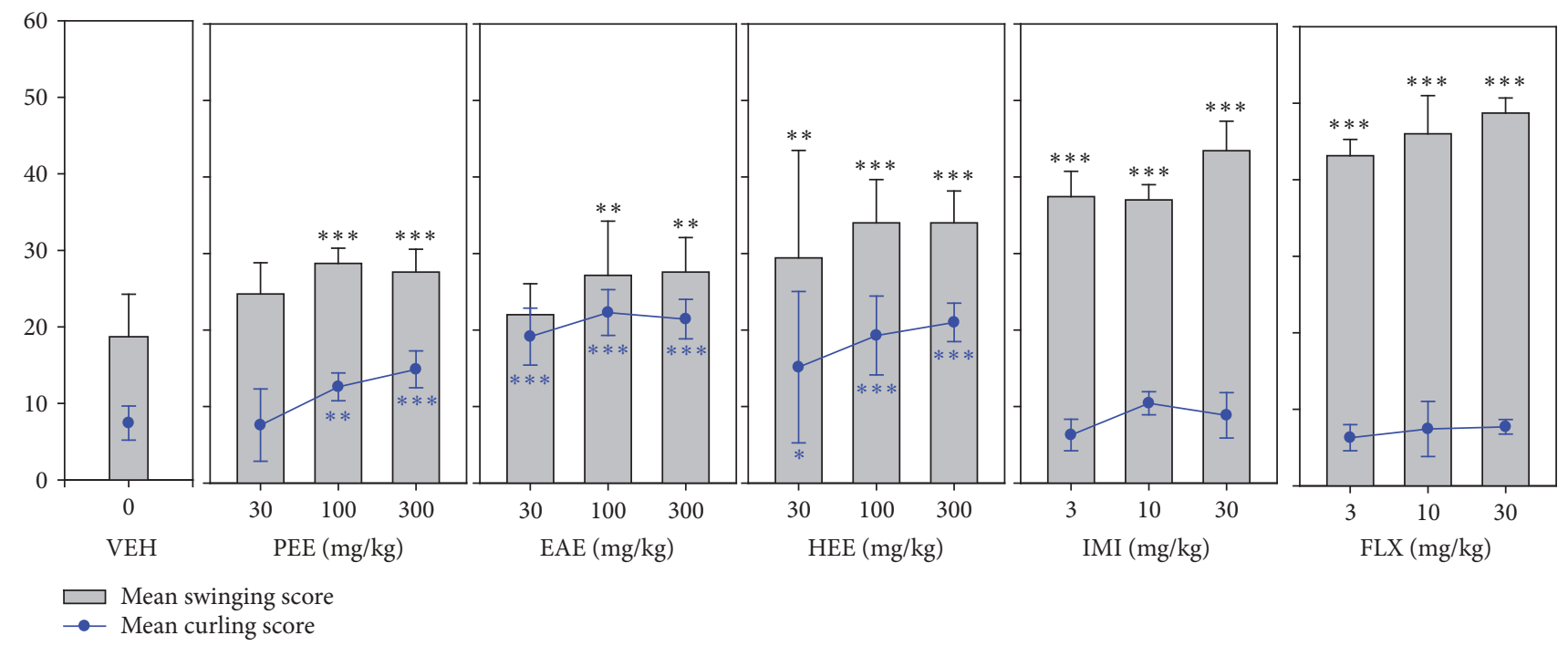

Figure 2: Effects of the extracts, PEE (30-300 mg/kg), EAE (30-300 mg/kg), and HEE (30-300 mg/kg), fluoxetine (3-30 mg/kg), and imipramine $(3-30 \mathrm{mg} / \mathrm{kg})$ on mean swinging scores and curling scores in TST. Data are represented as group means \pm SEM $(n=7)$. Significantly different from vehicle: ${ }^{* * *} P<0.0001$; ${ }^{* *} P<0.001$; and ${ }^{*} P<0.05$ (one-way ANOVA followed by Newman-Keuls test).

\subsection{Neurobehavioural Effects of the Components Extracted from HEE in the Forced Swimming Test (FST)}

3.6.1. Mean Immobility Score. All five components (FLV, TAN, ALK, TER, and SAP) significantly decreased immobility score $\left(F_{9,60}=101.7 P<0.0001 ; F_{9,60}=164.4 P<0.0001\right.$; $F_{9,60}=91.43 P<0.0001 ; F_{9,60}=82.12 P<0.0001 ; F_{9,60}$ $=72.80 P<0.0001$, resp.) (Figure 7). In FST, the order of antidepressant efficacy calculated from the dose response curve with regard to immobility score was fluoxetine $>$ ALK $>$ SAP $>$ FLV $>$ TER $>$ TAN (Table 4 ).

3.6.2. Possible Contribution of Serotoninergic and Noradrenergic Mechanisms in Antidepressant Effect: Mean Swimming and Climbing Scores. All five components (FLV, TAN, ALK, TER, and SAP) induced significant increases in swimming behaviour $\left(F_{9,60}=58.08 P<0.0001 ; F_{9,60}=93.05 P<0.0001\right.$; $F_{9,60}=69.09 P<0.0001 ; F_{9,60}=89.25 P<0.0001 ; F_{9,60}=$ 


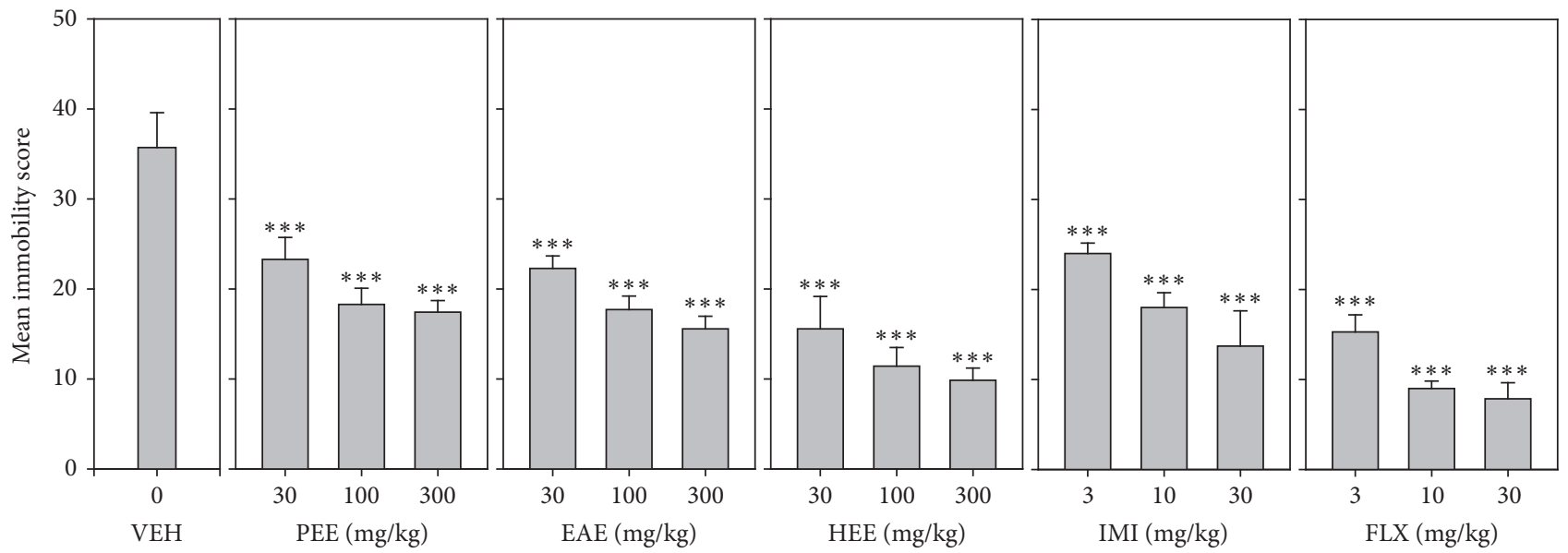

Figure 3: Effects of the extracts, PEE (30-300 mg/kg), EAE (30-300 mg/kg), and HEE (30-300 mg/kg), fluoxetine (3-30 mg/kg), and imipramine $(3-30 \mathrm{mg} / \mathrm{kg})$ on immobility score in FST. Data are represented as group means \pm SEM $(n=7)$. ${ }^{* * *} P<0.0001$; compared to vehicle-treated group (one-way ANOVA followed by Newman-Keuls test).

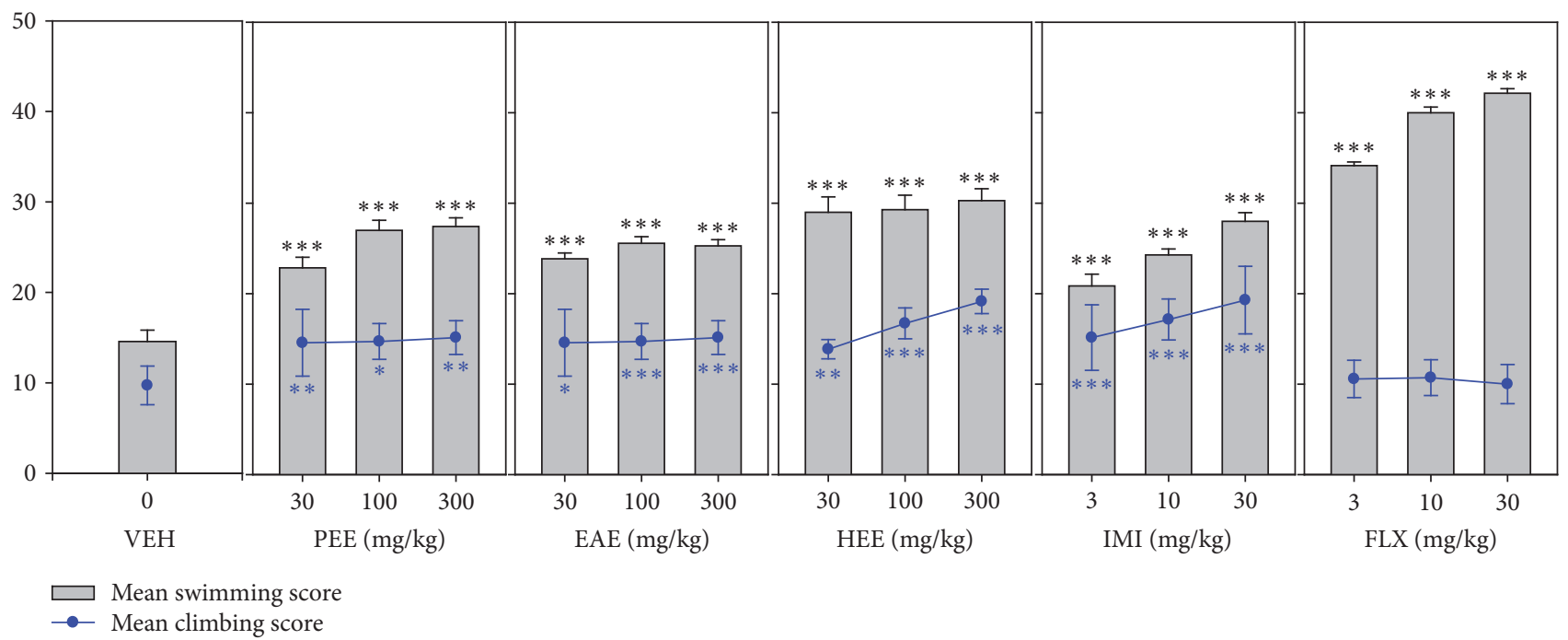

Figure 4: Effects of the extracts, PEE (30-300 mg/kg), EAE (30-300 mg/kg), and HEE (30-300 mg/kg), fluoxetine (3-30 mg/kg), and imipramine $(3-30 \mathrm{mg} / \mathrm{kg})$ on mean swimming and climbing scores in FST. Data are represented as group means \pm SEM $(n=7) .{ }^{*} P<0.05$; ${ }^{* *} P<0.001$; ${ }^{* * *} P<0.0001$; compared to vehicle-treated group (one-way ANOVA followed by Newman-Keuls test).

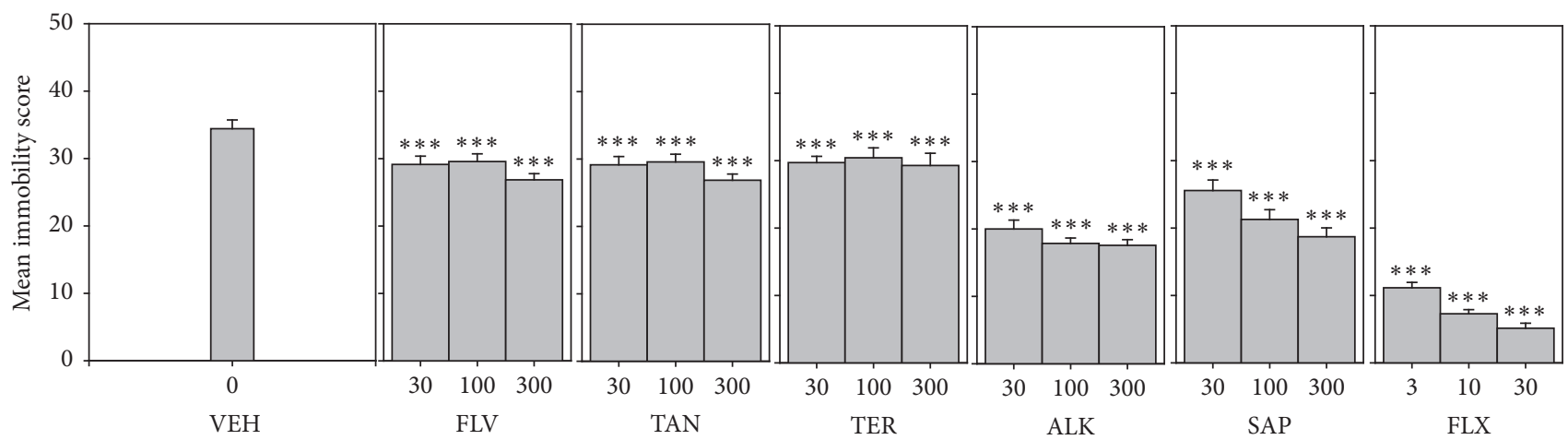

Figure 5: Effects of the components, FLV (30-300 mg/kg), TAN (30-300 mg/kg), ALK (30-300 mg/kg), TER (30-300 mg/kg), and SAP $(30-300 \mathrm{mg} / \mathrm{kg})$, and fluoxetine $(3-30 \mathrm{mg} / \mathrm{kg})$ on immobility score in TST. Data are represented as group means \pm SEM. Significantly different from vehicle: ${ }^{* * *} P<0.0001$ (one-way ANOVA followed by Newman-Keuls test). 

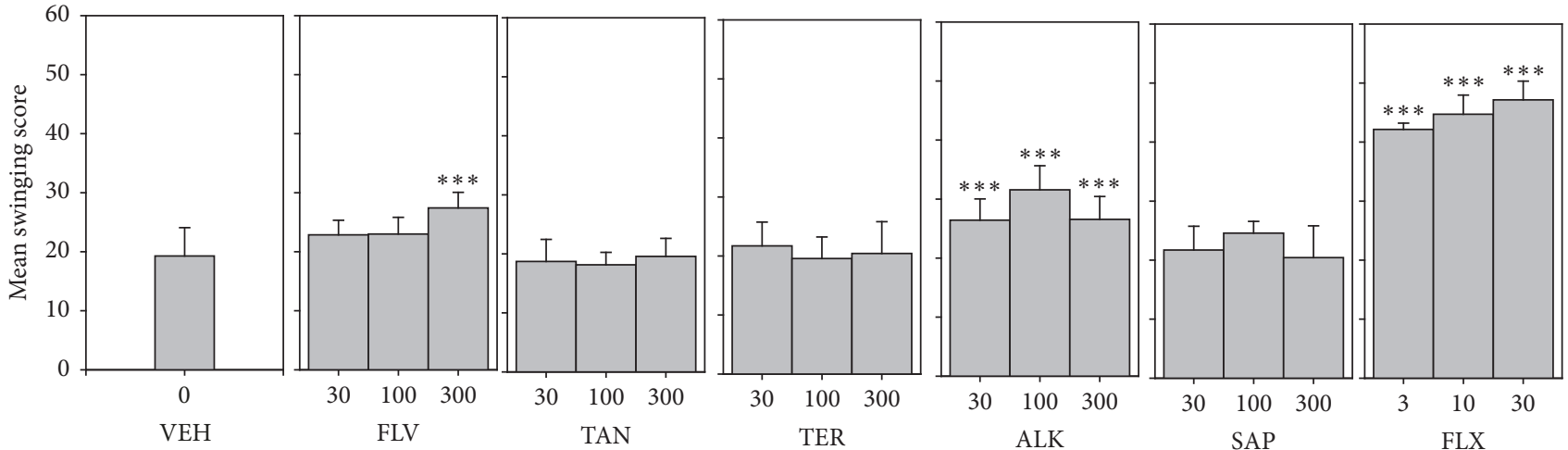

(a)
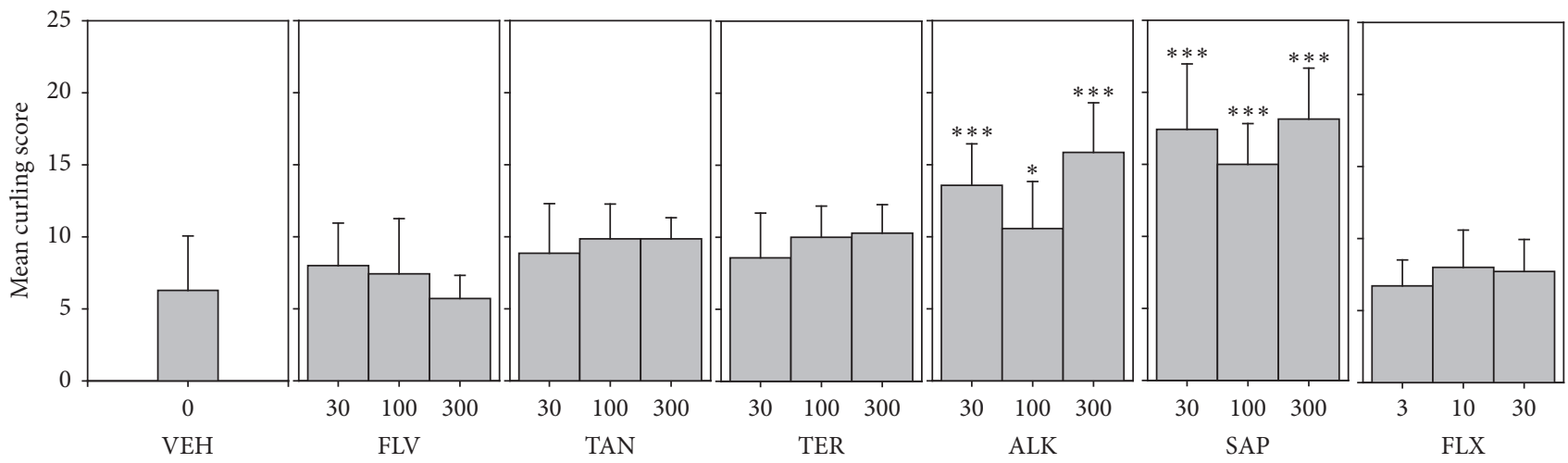

(b)

FIGURE 6: Effects of the components, FLV (30-300 mg/kg), TAN (30-300 mg/kg), ALK (30-300 mg/kg), TER (30-300 mg/kg), and SAP $(30-300 \mathrm{mg} / \mathrm{kg})$, and fluoxetine $(3-30 \mathrm{mg} / \mathrm{kg})$ on mean swinging scores and curling scores in the TST. Data are represented as group means $\pm \operatorname{SEM}(n=7)$. Significantly different from vehicle: ${ }^{* * *} P<0.0001 ;{ }^{*} P<0.05$ (one-way ANOVA followed by Newman-Keuls test).
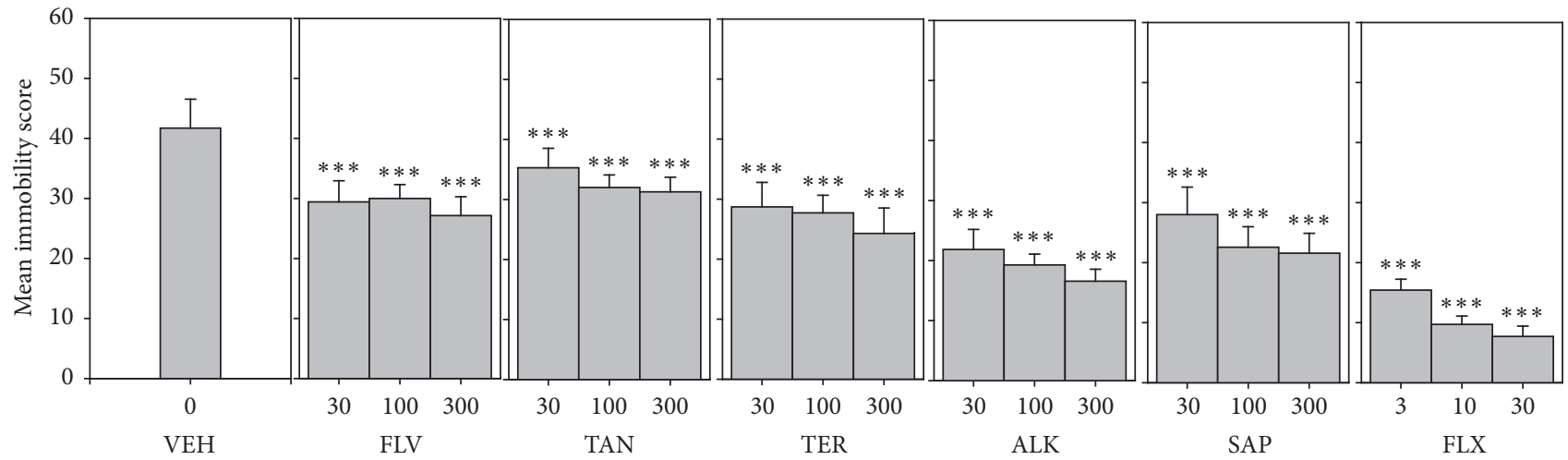

FIGURE 7: Effects of the components, FLV (30-300 mg/kg), TAN (30-300 mg/kg), ALK (30-300 mg/kg), TER (30-300 mg/kg), and SAP $(30-300 \mathrm{mg} / \mathrm{kg})$, and fluoxetine $(3-30 \mathrm{mg} / \mathrm{kg})$ on immobility score in FST. Data are represented as group means \pm SEM. Significantly different from vehicle: ${ }^{* * *} P<0.0001$ (one-way ANOVA followed by Newman-Keuls test).

$42.95 P<0.0001$, resp.) as did fluoxetine. Only SAP, TER, and ALK showed a significant increase in mean climbing scores $\left(F_{9,60}=10.52 P<0.0001 ; F_{9,60}=7.907 P<0.0001 ; F_{9,60}=\right.$ $12.78 P<0.0001$, resp.). See Figure 8 .

\section{Discussion}

Results from the present study have demonstrated that oral administration of the hydroethanolic, ethyl acetate, and petroleum ether extracts of the stem bark of Trichilia monadelpha possesses significant antidepressant-like activity without demonstrable impairment in locomotor activity or toxic effects.

All three extracts being investigated caused significant reductions in immobility behaviour, which is considered as the principal index for antidepressant efficacy [32] with a concomitant increase in active behaviours such as swimming, 

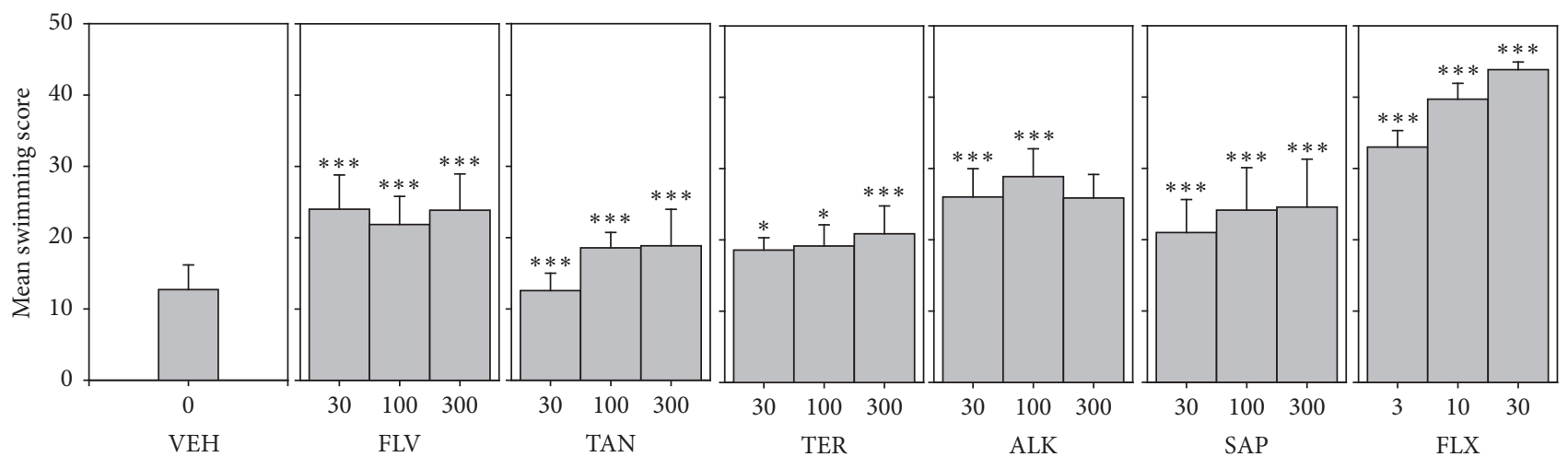

(a)
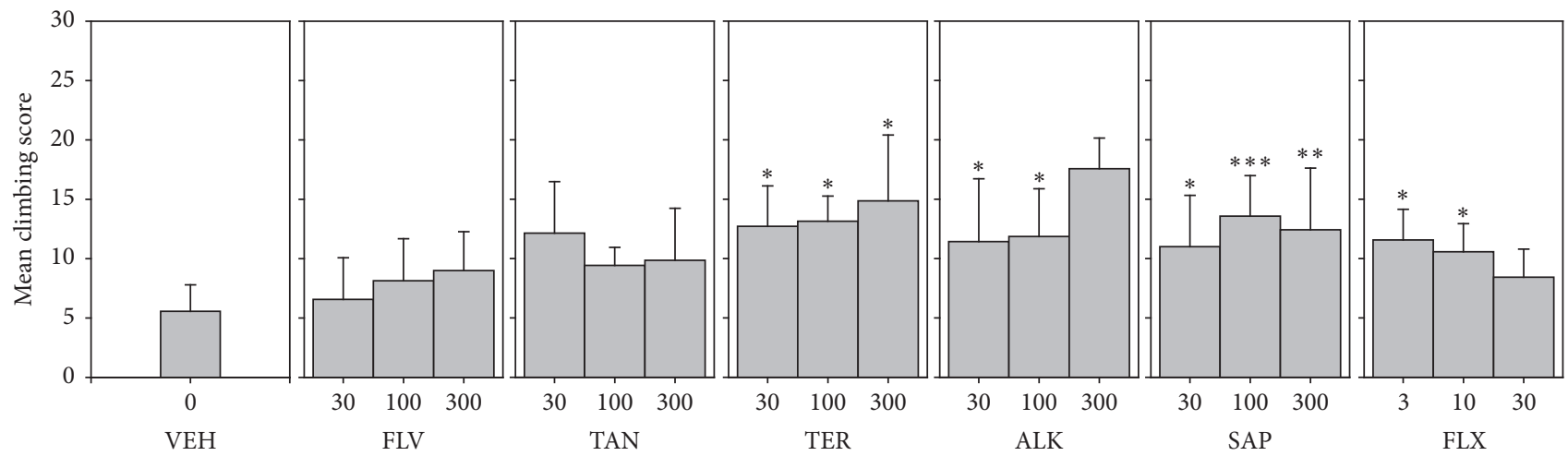

(b)

Figure 8: Effects of the components, FLV (30-300 mg/kg), TAN (30-300 mg/kg), ALK (30-300 mg/kg), TER (30-300 mg/kg), and SAP $(30-300 \mathrm{mg} / \mathrm{kg})$, fluoxetine $(3-30 \mathrm{mg} / \mathrm{kg})$, and imipramine $(3-30 \mathrm{mg} / \mathrm{kg})$ on mean swimming and climbing scores in FST. Data are represented as group means \pm SEM $(n=7)$. Significantly different from vehicle: ${ }^{*} P<0.05 ;{ }^{* * *} P<0.0001{ }^{* * *} P<0.001$ (one-way ANOVA followed by Newman-Keuls test).

TABLE 3: $\mathrm{ED}_{50}$ and $E_{\max }$ values of extracts and test drugs in TST and FST.

\begin{tabular}{cccc}
\hline \multirow{2}{*}{ Test } & \multirow{2}{*}{ Drug } & \multicolumn{2}{c}{ Decrease in immobility } \\
& & $\mathrm{ED}_{50}$ & $E_{\max }$ \\
\hline \multirow{4}{*}{ TST } & FLX & $1.58 \pm 0.2$ & 90.0 \\
& IMI & $4.32 \pm 1.1$ & 78.01 \\
& PEE & $196.10 \pm 12.2$ & 42.43 \\
& EAE & $66.83 \pm 5.6$ & 61.51 \\
& HEE & $26.64 \pm 3.6$ & 75.44 \\
\hline \multirow{3}{*}{ FST } & FLX & $2.88 \pm 0.6$ & 81.79 \\
& IMI & $10.86 \pm 1.5$ & 66.74 \\
& PEE & $132.20 \pm 14.2$ & 54.40 \\
& EAE & $108.70 \pm 10.6$ & 59.34 \\
& HEE & $35.92 \pm 2.0$ & 80.55 \\
\hline
\end{tabular}

climbing, curling, and swinging. Several reports indicate that all antidepressants in clinical use induce a decrease in immobility in rodents while other drugs devoid of antidepressant potential fail to give the same response [33].

The primary aim of the Irwin test, a CNS core battery test, is to assess the effects of a test substance on the behavioural and physiological functions and to reasonably estimate safe
TABLE 4: $\mathrm{ED}_{50}$ and $E_{\max }$ values of components and test drugs in TST and FST.

\begin{tabular}{cccc}
\hline \multirow{2}{*}{ Test } & \multirow{2}{*}{ Drug } & \multicolumn{2}{c}{ Decrease in immobility } \\
& & $\mathrm{ED}_{50}$ & $E_{\max }$ \\
\hline \multirow{3}{*}{ TST } & FLX & $1.86 \pm 0.8$ & 96.0 \\
& IMI & $4.58 \pm 1.2$ & 95.40 \\
& FLV & $912.80 \pm 19.2$ & 20.70 \\
& ALK & $122.70 \pm 11.4$ & 71.10 \\
& SAP & $227.20 \pm 113.9$ & 55.30 \\
\hline \multirow{3}{*}{ FST } & FLX & $2.21 \pm 1.2$ & 98.30 \\
& IMI & $6.80 \pm 1.8$ & 98.00 \\
& FLV & $376.70 \pm 14.2$ & 40.50 \\
& TAN & $1348.00 \pm 23.7$ & 24.80 \\
& ALK & $83.15 \pm 6.30$ & 76.40 \\
& TER & $408.80 \pm 14.8$ & 40.3 \\
& SAP & $141.10 \pm 12.4$ & 66.1 \\
\hline
\end{tabular}

dose ranges as well as potential lethal dose of a test drug [23, 34]. In the primary observation test, all three extracts (PEE, EAE, and HEE) demonstrated some sedative effects at higher doses (300-3000 $\mathrm{mg} / \mathrm{kg}$ ) without any deteriorating effect on respiration. This is an indication of a possible CNS depressant 
effect in all three extracts. Moreover all three extracts also showed analgesic even at lower doses. The observed analgesic effect in the primary observation test confirms earlier reports by Woode et al., [19]. Even at $3000 \mathrm{mg} / \mathrm{kg}$, all three extracts did not induce any observable adverse effects and there were no deaths after 24 hours. These results suggest that the $\mathrm{LD}_{50}$ of the three extracts are above $3000 \mathrm{mg} / \mathrm{kg}$, making it safe in the animals used.

In the FST, all three extracts demonstrated antidepressant effect by reducing the duration in immobility and increasing both swimming and climbing scores. Several reports indicate that drugs such as fluoxetine, sertraline, and paroxetine that selectively increase swimming without affecting climbing scores act via the serotoninergic pathway whereas selective noradrenaline uptake inhibitors, desipramine and maprotiline, selectively increased climbing without modifying swimming behaviours of rodents in FST [35]. Thus the observed behavioural effects of all the three extracts seem to suggest that they may be acting via both the serotoninergic and noradrenergic pathway.

In the TST, all three extracts showed antidepressant-like behaviour by inducing a significant reduction in immobility score and also caused increase in both swinging and curling behaviours. Berrocoso and colleagues have reported that compounds that demonstrate increase in curling may be acting via the opioidergic pathway while those that increase swinging score may be enhancing monoaminergic neurotransmission [36]. The findings thus suggest an interplay of monoaminergic and opioidergic activities for all the extracts. Antidepressants which inhibit reuptake of monoamines such as noradrenaline and serotonin have been reported to mediate the enhancement of the opioidergic neurotransmission [37]. The opioidergic system appears to be involved in the antidepressant efficacy of drugs like milnacipran, clomipramine, and so on, whose clinical effectiveness is mediated via $\mu$ opioid receptors [38]. In addition, several clinical studies have reported on the use of some $\mu$ opioid receptor agonists as antidepressants in managing refractory depression [39]. The role of the extracts in the enhancement of opioidergic neurotransmission confirms earlier reports that the analgesic effects of these extracts are partially mediated by the opioidergic pathway [19].

Moreover, the roles of inflammation and inflammatory mediators such as tumour necrosis factor (TNF), interleukins (IL), and C-reactive proteins in the pathophysiology of neuropsychiatric conditions like depression have been well documented [40]. Recent scientific study reported that extracts from T. monadelpha inhibited TNF- $\alpha$ and IL- 6 secretion [20]. This may be a plausible mechanism by which the extracts exhibit their antidepressant effect.

Numerous scientific reports have indicated that the pharmacological and therapeutic potentials of medicinal plants are due to the presence of active biological compounds most of which are components $[41,42]$. Thus the presence of the phytochemicals in the stem bark of T. monadelpha may be responsible for the observed neurobehavioural effects.

The results from the present study indicate that total alkaloid, saponins, flavonoids, terpenoids, and tannins from the most efficacious and potent extract, hydroethanolic extract, possess antidepressant effects in the FST and TST. This suggests that all the components tested contribute to the observed behavioural effect of the hydroethanolic extract. Since the total alkaloid fraction induced increased swimming, climbing, and swinging as well as curling behaviour, it is plausible that its antidepressant effect is dependent on a complex interplay of serotoninergic, catecholaminergic, and opioidergic mechanisms.

It is worth reporting that the efficacy of the individual phytoconstituents was lower than that of the total hydroethanolic extract. It is plausible that the antidepressant efficacy observed in the hydroethanolic extract can be attributed to the synergistic effect produced by the individual active phytoconstituents and possibly via varying mechanisms of action [43].

\section{Conclusion}

The present study shows that components present in the stem bark of Trichilia monadelpha have antidepressant-like effect in mice.

\section{Limitation of Study}

This study was conducted in mice. Though there are some genetic similarities between mice and humans, results cannot be extrapolated to humans until further tests are conducted.

\author{
Abbreviations \\ ALK: Alkaloids \\ EAE: Ethyl acetate extract \\ FLV: Flavonoids \\ HEE: Hydroethanolic extract \\ FLX: Fluoxetine \\ FST: Forced swimming test \\ IMI: Imipramine \\ ICR: Imprinting control region \\ p.o.: Per os \\ PEE: Petroleum ether extract \\ SAP: Saponins \\ TAN: Tannins \\ TER: Terpenoids \\ TST: Tail suspension test.
}

\section{Conflicts of Interest}

The authors declare that they have no conflicts of interest.

\section{Acknowledgments}

The authors wish to thank the technicians from the Department of Pharmacology and Toxicology, University of Ghana, for their technical support. This study was funded by the University of Ghana Research Fund with Grant no. URF/7/SF011/2013-2. 


\section{References}

[1] K. Pytka, A. Dziubina, K. Młyniec et al., "The role of glutamatergic, GABA-ergic, and cholinergic receptors in depression and antidepressant-like effect," Pharmacological Reports, vol. 68, no. 2, pp. 443-450, 2016.

[2] R. C. Kessler and E. J. Bromet, "The epidemiology of depression across cultures," Annual Review of Public Health, vol. 34, pp. 119138, 2013.

[3] K. Młyniec, M. Gaweł, U. Doboszewska et al., "Essential elements in depression and anxiety. Part II," Pharmacological Reports, vol. 67, no. 2, pp. 187-194, 2015.

[4] Z. Shahamat, S. Abbasi-Maleki, and M. S. Mohammadi, "Evaluation of antidepressant-like effects of aqueous and ethanolic extracts of Pimpinella anisum fruit in mice," Avicenna Journal of Phytomedicine, vol. 6, no. 3, pp. 322-328, 2016.

[5] J. Shen, J. Zhang, M. Deng, Y. Liu, Y. Hu, and L. Zhang, "The antidepressant effect of Angelica sinensis extracts on chronic unpredictable mild stress-induced depression is mediated via the upregulation of the BDNF signaling pathway in rats," Evidence-Based Complementary and Alternative Medicine, vol. 2016, Article ID 7434692, 8 pages, 2016.

[6] E. Poleszak, B. Szewczyk, E. Kędzierska, P. Wlaź, A. Pilc, and G. Nowak, "Antidepressant- and anxiolytic-like activity of magnesium in mice," Pharmacology Biochemistry \& Behavior, vol. 78, no. 1, pp. 7-12, 2004.

[7] K. K. Kukuia, P. K. Mante, E. Woode, E. O. Ameyaw, and D. W. Adongo, "Antidepressant effects of mallotus oppositifolius in acute murine models," ISRN Pharmacology, vol. 2014, Article ID 324063, 12 pages, 2014.

[8] E. J. Nestler, M. Barrot, R. J. DiLeone, A. J. Eisch, S. J. Gold, and L. M. Monteggia, "The neurobiology of depression," Neuron, vol. 34, no. 1, pp. 13-25, 2002.

[9] Mouhssen L., "The success of natural products in drug discovery," Pharmacology \& Pharmacy, vol. 4, no. 3, pp. 17-31, 2013.

[10] M. Aslam and N. Sultana, "Vitis vinifera juice ameliorates depression-like behavior in mice by modulating biogenic amine neurotransmitters," Bangladesh Journal of Pharmacology, vol. 10, no. 4, pp. 753-758, 2015.

[11] M. Mirhosseini, A. Baradaran, and M. Rafeian-Kopaei, "Anethum graveolens and hyperlipidemia: a randomized clinical trial," Journal of Research in Medical Sciences, vol. 19, 2014.

[12] D. O. Kennedy and E. L. Wightman, "Herbal extracts and phytochemicals: plant components and the enhancement of human brain function," Advances in Nutrition, vol. 2, pp. 32-50, 2011.

[13] J. Gong, J. Huang, Q. Ge, F. Chan, and Y. Zhang, "Advanced research on the antidepressant effect of flavonoids," Current Opinion in Complementary and Alternative Medicine, vol. 1, no. 2, pp. 1-6, 2014.

[14] H. Dang, Y. Chen, X. Liu et al., "Antidepressant effects of ginseng total saponins in the forced swimming test and chronic mild stress models of depression," Progress in NeuroPsychopharmacology \& Biological Psychiatry, vol. 33, no. 8, pp. 1417-1424, 2009.

[15] L. Mander and H. Lui, "Natural products structural diversity-I components: organization and biosynthesis," in Comprehensive Natural Products II: C, C. Townsed and Y. Ebizuka, Eds., vol. 10, pp. 1061-1062, Chemistry and Biology: Elsevier, Kidlington, UK, 2010.
[16] M. Martínez-Vázquez, R. Estrada-Reyes, A. G. Araujo Escalona et al., "Antidepressant-like effects of an alkaloid extract of the aerial parts of Annona cherimolia in mice," Journal of Ethnopharmacology, vol. 139, no. 1, pp. 164-170, 2012.

[17] Y. P. Shi and H. Wang, "Antidepressant activity of extract of Hypericum perforatum with enriched flavonoids," Zhong Yao Xin Yao Yu Lin Chuang Yao Li, vol. 17, no. 1, pp. 4-7, 2006.

[18] H. Burkill, The Flora of West Tropical Africa, Royal Botanic Gardens, Kew, London, UK, 2nd edition, 1985.

[19] E. Woode, A. K. Amoh-Barimah, W. K. M. Abotsi, G. K. Ainooson, and G. Owusu, "Analgesic effects of stem bark extracts of Trichilia monadelpha (Thonn.) JJ de Wilde," Indian Journal of Pharmacology, vol. 44, no. 6, pp. 765-773, 2012.

[20] I. O. Ben, E. Woode, G. A. Koffuor, and E. A. Asiamah, "Antianaphylactic effects of Trichilia monadelpha (Thonn.) J. J. de Wilde extracts on rodent models of anaphylaxis," Research in Pharmaceutical Sciences, vol. 11, no. 5, pp. 397-404, 2016.

[21] N.R.C., "Guide for the care and use of laboratory animals," Institute of Laboratory Animals Research Commission on Life Science, The National Academic Press. Leicester (UK). NICE Clinical Guidelines 90, British Psychological Society, 1996.

[22] G. E. Trease and W. C. Evans, Textbook of Pharmacognosy, Balliere; Tindall, London, UK, 12th edition, 1989.

[23] S. Irwin, "System analysis: a strategy for drug experimentation and evaluation.," Perspectives in Biology and Medicine, vol. 11, no. 4, pp. 654-674, 1968.

[24] L. Steru, R. Chermat, B. Thierry, and P. Simon, "The tail suspension test: a new method for screening antidepressants in mice," Psychopharmacology, vol. 85, no. 3, pp. 367-370, 1985.

[25] R. D. Porsolt, M. Le Pichon, and M. Jalfre, "Depression: a new animal model sensitive to antidepressant treatments," Nature, vol. 266, no. 5604, pp. 730-732, 1977.

[26] A. Nahapetian and A. Bassiri, "Changes in concentrations and interrelations of phytate, phosphorus, magnesium, calcium, and zinc in wheat during maturation," Journal of Agricultural and Food Chemistry, vol. 23, no. 6, pp. 1179-1182, 1975.

[27] B. O. Obdoni and P. O. Ochuko, "Phytochemical studies and comparative efficacy of the crude extracts of some homostatic plants in Edo and Delta States of Nigeria," Global Journal of Pure and Applied Sciences, vol. 8, no. 2, pp. 203-208, 2001.

[28] J. B. Harborne, "Methods of plant analysis," in Phytochemical Methods, Chapman and Hall, London, UK, 1973.

[29] B. A. Bohm and R. Kocipai-Abyazan, "Flavonoid and condensed tannins from the leaves of Vaccinum raticulation and Vaccinum calcyimium," Pacific Science, vol. 48, pp. 458-463, 1994.

[30] N. M. Ferguson, A Text Book of Pharmacognosy, Mac Milan Company, New Delhi, India, 1956.

[31] D. H. Strumeyer and M. J. Malin, "Condensed tannins in grain sorghum: Isolation, fractionation, and characterization," Journal of Agricultural and Food Chemistry, vol. 23, no. 5, pp. 909-914, 1975.

[32] J. F. Cryan, M. E. Page, and I. Lucki, "Differential behavioral effects of the antidepressants reboxetine, fluoxetine, and moclobemide in a modified forced swim test following chronic treatment," Psychopharmacology, vol. 182, no. 3, pp. 335-344, 2005.

[33] B. Petit-Demouliere, F. Chenu, and M. Bourin, "Forced swimming test in mice: a review of antidepressant activity," Psychopharmacology, vol. 177, no. 3, pp. 245-255, 2005.

[34] J. J. Lynch, V. Castagné, P. C. Moser, and S. W. Mittelstadt, "Comparison of methods for the assessment of locomotor 
activity in rodent safety pharmacology studies," Journal of Pharmacological and Toxicological Methods, vol. 64, no. 1, pp. 74-80, 2011.

[35] M. J. Detke, M. Rickels, and I. Lucki, "Active behaviors in the rat forced swimming test differentially produced by serotonergic and noradrenergic antidepressants," Psychopharmacology, vol. 121, no. 1, pp. 66-72, 1995.

[36] E. Berrocoso, K. Ikeda, I. Sora, G. R. Uhl, P. Sánchez-Blázquez, and J. A. Mico, "Active behaviours produced by antidepressants and opioids in the mouse tail suspension test," The International Journal of Neuropsychopharmacology, vol. 16, no. 1, pp. 151-162, 2013.

[37] E. M. Jutkiewicz and B. P. Roques, "Endogenous opioids as physiological antidepressants: Complementary role of delta receptors and dopamine," Neuropsychopharmacology, vol. 37, no. 1, pp. 303-304, 2012.

[38] A.-S. Wattiez, F. Libert, A.-M. Privat et al., "Evidence for a differential opioidergic involvement in the analgesic effect of antidepressants: Prediction for efficacy in animal models of neuropathic pain?" British Journal of Pharmacology, vol. 163, no. 4, pp. 792-803, 2011.

[39] N. A. Shapira, M. L. Verduin, and J. D. DeGraw, "Treatment of refractory major depression with tramadol monotherapy," Journal of Clinical Psychiatry, vol. 62, pp. 205-206, 2001.

[40] A. H. Miller and C. L. Raison, "The role of inflammation in depression: from evolutionary imperative to modern treatment target," Nature Reviews Immunology, vol. 16, no. 1, pp. 22-34, 2016.

[41] E. G. Maganha, R. D. C. Halmenschlager, R. M. Rosa, J. A. P. Henriques, A. L. L. D. P. Ramos, and J. Saffi, "Pharmacological evidences for the extracts and secondary metabolites from plants of the genus Hibiscus," Food Chemistry, vol. 118, no. 1, pp. $1-10,2010$.

[42] A. P. Rogerio, A. Sá-Nunes, and L. H. Faccioli, "The activity of medicinal plants and secondary metabolites on eosinophilic inflammation," Pharmacological Research, vol. 62, no. 4, pp. 298-307, 2010.

[43] D. P. Briskin, "Medicinal plants and phytomedicines. Linking plant biochemistry and physiology to human health," Plant Physiology, vol. 124, no. 2, pp. 507-514, 2000. 


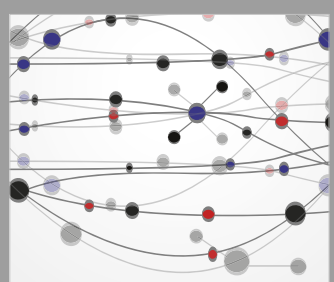

The Scientific World Journal
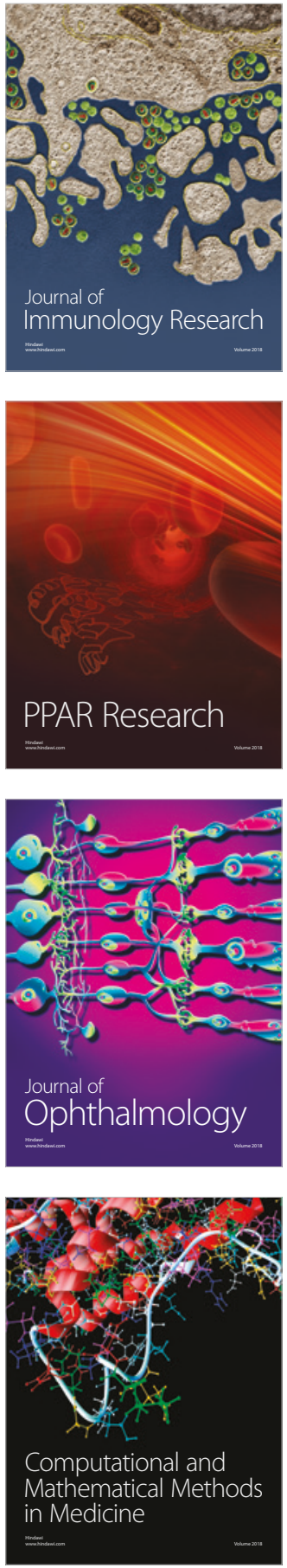

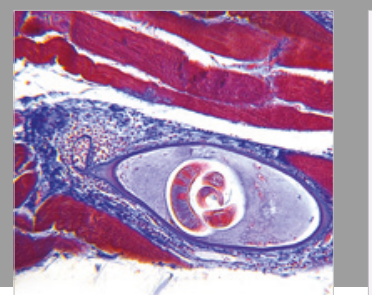

Gastroenterology Research and Practice

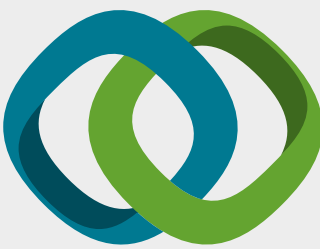

\section{Hindawi}

Submit your manuscripts at

www.hindawi.com
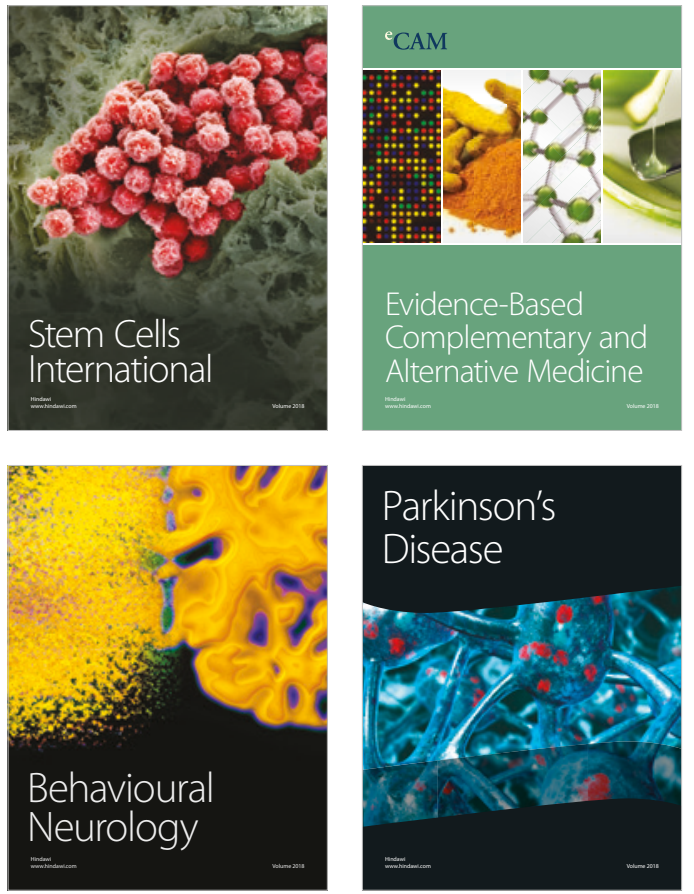

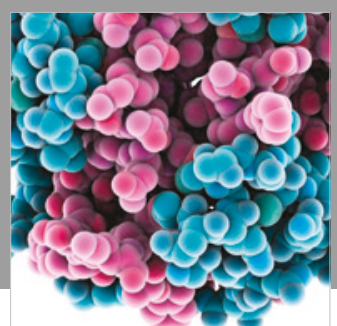

ournal of

Diabetes Research

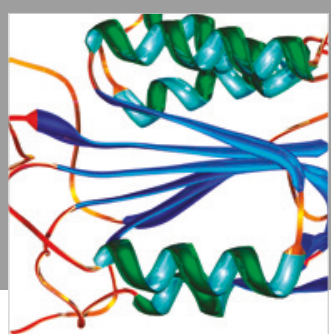

Disease Markers
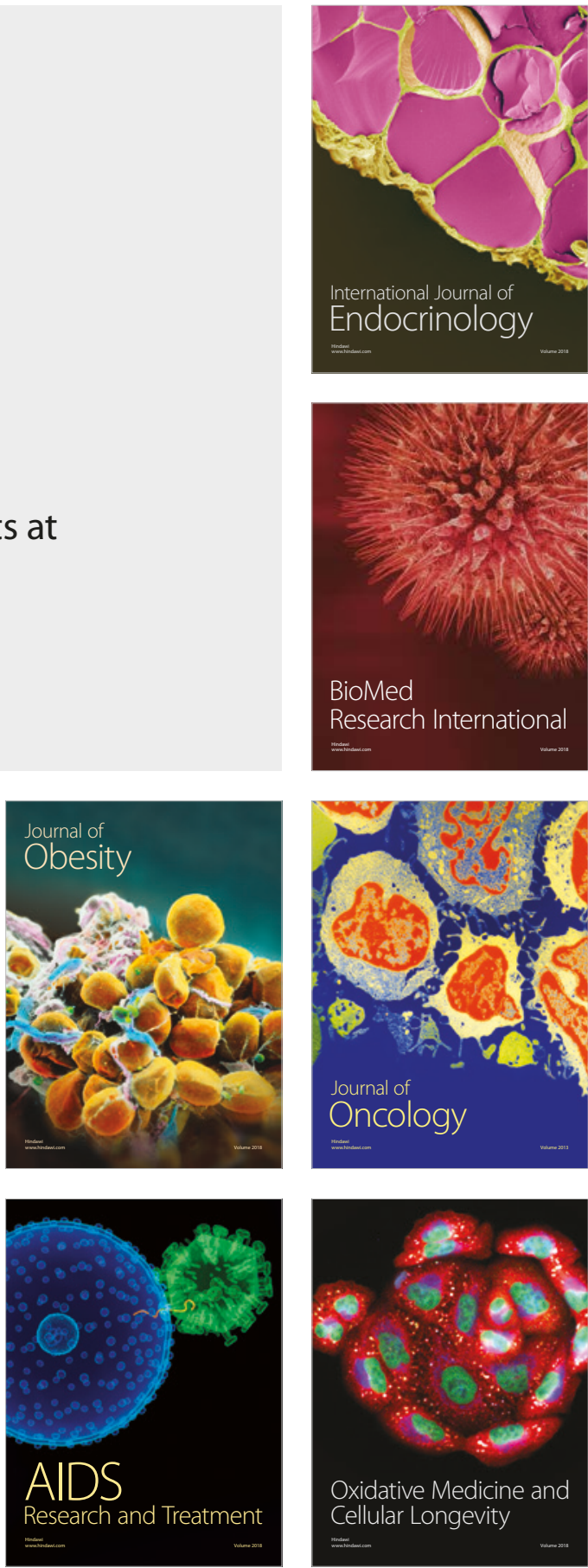